\title{
Ordem Consolata e povos indígenas do território federal do Rio Branco (1948-1952): estratégias de abordagem para inserção de cuidados
}

\author{
The Consolata Order and indigenous peoples in the federal territory \\ of Rio Branco (1948-1952): approaches for implementing care
}

\footnotetext{
Jacquelaine Alves Machado ${ }^{i}$

i Professora, Departamento de Ciências Socialmente Aplicadas/ Universidade Estadual de Roraima. Boa Vista - RR - Brasil

orcid.org/0000-0002-5523-6876

jacquelainealves@gmail.com

\section{Raphael Florindo} Amorim ${ }^{i i}$

ii Professor, Departamento de Enfermagem/Universidade Federal de Roraima.

Boa Vista - RR - Brasil orcid.org/0000-0002-7491-4257

raphael.amorim@ufrr.br

\section{Fernando Porto ${ }^{i i i}$}

iii Professor, Departamento de Enfermagem Materno-Infantil/Escola de Enfermagem Alfredo Pinto/ Universidade Federal do Estado do Rio de Janeiro.

Rio de Janeiro - RJ - Brasil orcid.org/0000-0002-2880-724X

fernando.porto@unirio.br

Recebido em 24 abr. 2019. Aprovado em 4 out. 2019.
}

MACHADO, Jacquelaine Alves; AMORIM, Raphael Florindo; PORTO, Fernando. Ordem Consolata e povos indígenas do território federal do Rio Branco (1948-1952): estratégias de abordagem para inserção de cuidados. História, Ciências, Saúde - Manguinhos, Rio de Janeiro, v.27, n.4, out.-dez. 2020, p.1341-1353.

Resumo

A pesquisa discute as estratégias de aproximação com os indígenas de Rio Branco empreendidas por missionários católicos da Ordem Consolata em meados do século XX. Matérias selecionadas do periódico Missioni Consolata foram submetidas ao protocolo texto, imagem e contexto e relacionadas aos conceitos de campo, luta e espaço social, na perspectiva do sociólogo Pierre Bourdieu. Duas matérias do periódico e seis imagens, mostrando estratégias dos religiosos para aproximação com os índios e introdução de cuidados, foram articuladas ao texto e ao contexto. Trazer à tona aspectos do passado, sem verniz religioso, para o uso de estratégias que podem passar despercebidas na política e no discurso em prol da saúde indígena foi a síntese da pesquisa.

Palavras-chave: cuidado religioso; cuidado cultural; interculturalidade.

\section{Abstract}

This study discusses the strategies used for approaching the indigenous peoples of Rio Branco by Catholic missionaries of the Consolata Order during the midtwentieth century. Articles selected from the Missioni Consolata publication were analyzed according to text, image, and context protocol and related to the concepts of field, struggle, and social space from the viewpoint of the sociologist Pierre Bourdieu. Two articles and six images showing strategies undertaken by the missionaries to approach indigenous people and introduce care were linked to the text and context. This analysis shows aspects of the past, without religious filters, related to the use of strategies that may pass unnoticed in politics and in discourse in favor of indigenous health.

Keywords: religious care; cultural care; interculturality. 
$\mathrm{N}$ o final do século XIX, a região Norte do Brasil foi marcada por intensos conflitos envolvendo a posse de terras e disputas políticas, cenário que se estenderia por décadas. Esse era o contexto da região do Rio Branco em 1909, quando os missionários católicos da ordem beneditina receberam da Igreja católica a incumbência de promover a catequização dos povos indígenas ali estabelecidos (Santilli, 2014).

Em 1948, chegaram ao então território federal do Rio Branco os primeiros missionários da Consolata (vinculados ao Instituto Missionários da Consolata - sediado em Turim, Itália), em substituição aos monges beneditinos. Nesse período, o país era presidido por Eurico Gaspar Dutra, cujo mandato encerrou-se em 1951, quando assumiu o presidente Getúlio Vargas. Isso posto, temos o questionamento: quais foram as estratégias empreendidas pela Ordem Consolata para aproximação com os índios da região de Rio Branco?

A justificativa para a realização do estudo se pauta pelo imaginário de que a presença religiosa na dita catequese dos índios ocorreu em séculos anteriores, como é ensinado na educação básica. Vislumbrar que o fato ocorreu ainda no século XX é chamar a atenção para o poderio religioso e possibilitar o avanço sobre o entendimento das estratégias empreendidas pelos religiosos no norte do país. Isso implica extrapolar para além dos estudos sobre campos político, social e cultural a fim de dialogar com a área da saúde e entender as políticas vigentes para o segmento da saúde indígena.

Os estudos a respeito do campo religioso e, particularmente, do contexto das missões religiosas têm sido alvo de interesse de pesquisadores ao redor do mundo. Chiara Vangelista, desde meados da década de 1990, dedica-se à pesquisa envolvendo os povos indígenas da região Centro-Oeste do Brasil, em especial com os índios bororo em Mato Grosso, que desenvolveram interações estreitas com os missionários italianos salesianos.

Esses missionários, de acordo com Vangelista (1996), operacionalizaram, no início do século XX, intenso trabalho de catequização/conversão daqueles indígenas, atuando juntamente com o Estado nas frentes de expansão fronteiriça da região, empregando estratégias de evangelização que tiveram como foco a introdução direta e incisiva de princípios cristãos e desestruturação de ritos e costumes indígenas. No entanto, os salesianos, naquele período de intensos conflitos, representaram para os autóctones lugar de conforto e atenuante das drásticas medidas que eram tomadas em relação à ocupação de suas terras.

A obra de Montero (2006) traz em seu bojo ampla discussão sobre os códigos de comunicação resultantes das interações entre missionários (oriundos de distintas organizações religiosas) e indígenas. A autora explorou o aspecto da alteridade, contemplando a cosmologia indígena, aspectos antropológicos e o conjunto de códigos simbólicos gerados a partir de um processo de "desconstrução e reconstrução" de códigos comunicativos. Nesse aspecto, Montero demonstra consenso com Gasbarro (2006), que investigou em sua obra as missões religiosas no contexto das civilizações.

Destacamos ainda os estudos de Silva e Araújo (2007), que analisaram a perspectiva da mediação cultural e dos códigos simbólicos de comunicação. Para tanto, pesquisaram as interações entre missionários salesianos com os índios bororo meruri no estado do Mato Grosso e o trabalho dos missionários italianos da Consolata com os índios da etnia macuxi em Roraima.

Castelnau-L'Estoile (2013) analisou as interações entre os missionários capuchinhos franceses com os índios tupi do Maranhão no início do século XVII, avaliando a introdução de pressupostos da vida cristã no cotidiano daqueles povos. 
Com interesse pelo trabalho das missões religiosas, em especial as missões católicas, por sua incisiva atuação na Amazônia, nosso objetivo foi discutir as estratégias de aproximação com os indígenas empreendidas pelos missionários da Consolata em meados do século XX.

O estudo qualitativo, de método histórico, enfatizou a microanálise do caso da atuação da Ordem Consolata no território federal do Rio Branco, hoje estado de Roraima. ${ }^{1}$ A delimitação temporal foi compreendida de 1948 a 1952, tendo por fatos balizadores a chegada da Ordem Consolata em Boa Vista e a consequente inserção cultural dos missionários no espaço social indígena.

As fontes históricas foram oriundas da revista Missioni Consolata, publicação do Instituto Missionários da Consolata, sediado em Turim, na Itália, e cuja editoração ocorria no mesmo local. O periódico circulava mundialmente no âmbito da Igreja católica. Pela origem das fontes, o olhar se deu a partir dos religiosos, mas isso não significou endogenia, pois utilizamos como suporte a razão crítica (Osório, 2005).

Trabalho semelhante foi desenvolvido por Freire (2006), cujos estudos abordaram a maternidade, com foco no cuidado aos recém-nascidos, dentro das perspectivas empírica e científica. A autora analisou matérias, fotografias e anúncios relacionados à temática, presentes em duas revistas direcionadas ao público feminino na década de 1920, ambas de circulação no estado do Rio de Janeiro.

O uso de fotografias como fonte histórica é contemplado nas obras de Ana Maria Mauad. Em "Através da imagem: fotografia e história interfaces", Mauad (1996) destaca a importância da transdisciplinaridade na relação da fotografia com os aspectos sociológico e antropológico, devido à importância de apurar, com a profundidade necessária, os conteúdos que trafegam ao redor de uma imagem fotográfica.

Ainda nesse contexto, utilizamos como exemplos a pesquisa "Enfermeira na imprensa ilustrada brasileira (1890-1925): assinatura imagética", de Porto e Neto (2014), e o estudo de Bernardes et al. (2015) "Método de análise imagética: Cazuza na revista Veja como ícone da aids na década de 1980 no Brasil", utilizando textos e imagens fotográficas da imprensa ilustrada (jornais e revistas).

As matérias da revista Missioni Consolata receberam tratamento analítico, tendo sido submetidas ao processo de triangulação de dados, que possibilita a longevidade do texto de pesquisa e estudos futuros com análises distintas sob ângulos diferentes (Porto, Freitas, Gonzáles, 2009).

No processo de análise da massa documental da pesquisa, adotamos como critério de inclusão: as narrativas e imagens retratando o anúncio da chegada da Ordem Consolata em Roraima; o processo de interação dos missionários dentro das comunidades indígenas; e imagens retratando os costumes e habitus indígenas. Foram excluídas imagens e narrativas específicas do estado do Amazonas e também as que retratavam a flora e a fauna da região.

A discussão dos resultados se deu com base na documentação selecionada, encontrada em matérias veiculadas nas edições n.5 de 1949 (maio), n.10 de 1951 (outubro) e n.6 de 1952 (junho) da Missioni Consolata, todas em língua italiana. Essas sofreram o processo de transcriação para o exame documental e a tradução dos textos (Gerônimo, 2014).

Neste estudo, exploramos o discurso imagético de matérias veiculadas na revista. Isso implicou um trabalho de seleção do que era publicado no periódico religioso, com análise 
de figuras articuladas ao texto, dando origem a críticas, embasadas por referencial teórico e por uma literatura de aderência, apresentadas em meio ao texto e nas considerações finais, deslocando o foco da crença religiosa para o aspecto sociocultural articulado com base nos estudos teóricos de Pierre Bourdieu.

Com relação aos aspectos éticos e legais, nos respaldamos na Resolução do Conselho Nacional de Saúde n.510, de 7 de abril de 2016, articulada à lei n.9.610, de 19 de fevereiro de 1998, que altera, atualiza e consolida a legislação sobre direitos autorais e dá outras providências.

\section{A missão}

Em 1902, o Instituto Missionários da Consolata designou a primeira Missão Consolata, com destino ao Quênia, país que enfrentava um dos mais violentos processos anticoloniais africanos com a guerrilha Mau Mau (Araújo, 2007). Após o conflito, com o processo de organização do Quênia estabelecido, os missionários religiosos passaram a se deslocar para outros locais, vindo então para o território federal do Rio Branco.

Em 1948, o monsenhor Giusepe Nepote Fus foi designado para assumir a prelazia do Rio Branco e liderar um grupo de sete missionários. A chegada dos Consolata foi veiculada na revista Missioni Consolata em 1949. Antes de partirem para Rio Branco, cita o registro que eles ficaram em São Paulo para aprendizagem da língua portuguesa.

O cenário encontrado pelos missionários foi de conflitos envolvendo disputas de terras, em decorrência das invasões de territórios indígenas em séculos anteriores, o que fez os nativos migrarem para as margens dos rios da região em busca de sobrevivência. Isso após o período de exploração de sua mão de obra pelos antigos colonizadores e invasores (portugueses e espanhóis) e, na década de 1940, a disputa com os garimpeiros em busca das riquezas minerais da região (Vieira, Gomes Filho, jul.-dez. 2015).

Nesse momento, deparamo-nos com um campo fértil de lutas. Isso nos aponta para o conceito de campo adjetivado de lutas. Trata-se de lugares em que a produção reside em conservar ou transformar as relações de força instituídas, visando a efeitos na estrutura sociocultural. Logo, os agentes envolvidos precisaram tomar posições, o que compreendeu o acúmulo de capital constituído pelo habitus, pela conservação ou pela transformação na estrutura (Bourdieu, 1996).

As regras estabelecidas, portanto, encontravam-se em risco, especialmente no lastro das lutas anteriores em busca de soluções para a reconfiguração do espaço social. Pensar nessa perspectiva era resgatar o passado dos índios, que foram explorados pelos colonizadores portugueses e pelos invasores espanhóis. Isso evidencia, por um lado, menor força, por terem migrado para as margens dos rios, por outro lado, resistência, por terem reconfigurado seu espaço social.

Sabemos também que, no passado, religiosos intermediavam e possivelmente influenciavam a reconfiguração do espaço social indígena e seu habitus. Isso porque cabia aos missionários "civilizá-los" para os interesses do Estado. Neste momento, fazemos uma pausa, antes de nos posicionar. Faz-se necessário o esclarecimento de três termos a ser empregados a favor da crítica - julgar, defender e liberdade. 
Defender a crítica é ir contra a vinculação entre julgar e condenar, ou enquadrar. Para tanto, o termo deve ser entendido como dissenso, e não consenso, ou seja, diferenciar, produzir distinções. Isso também induz a defender a liberdade que compromete e surpreende, pois a liberdade é solo fértil no campo político (Silva, Araújo, 2007).

As estratégias para a reconfiguração do espaço social indígena mediante outros agentes não significou ganhar ou perder. Implicou acumular capital e reconfigurar o campo de luta em prol de seu espaço social. Convém ter um olhar sobre os indígenas fora do senso comum, como resistentes e não vulneráveis. Se eles eram manipulados, também manipulavam tendo em vista seus interesses de conservação do habitus, mesmo que reconfigurado. Isso se deu não pela materialização estética de seus trajes, por exemplo, mas pelas tradições simbólicas e culturais preservadas (Pereira, 2015).

\section{Imersão na cultura do índio}

Na mesma edição de 1949 da Missioni Consolata, foi possível localizar registros dos dados geográficos e demográficos de Rio Branco. A matéria aborda a dificuldade de precisar o quantitativo populacional, mas o estimava de 20 a 50 mil pessoas, sendo 3/4 formados por pessoas civilizadas, majoritariamente nordestinas, e 1/4 composto por pessoas nativas. Afirmam que a população era corajosa e ressaltam a dificuldade de acesso às áreas adjacentes a Rio Branco. Para ilustrar, fizeram registro em imagem de meio de transporte pelos rios da região (Figura 1).

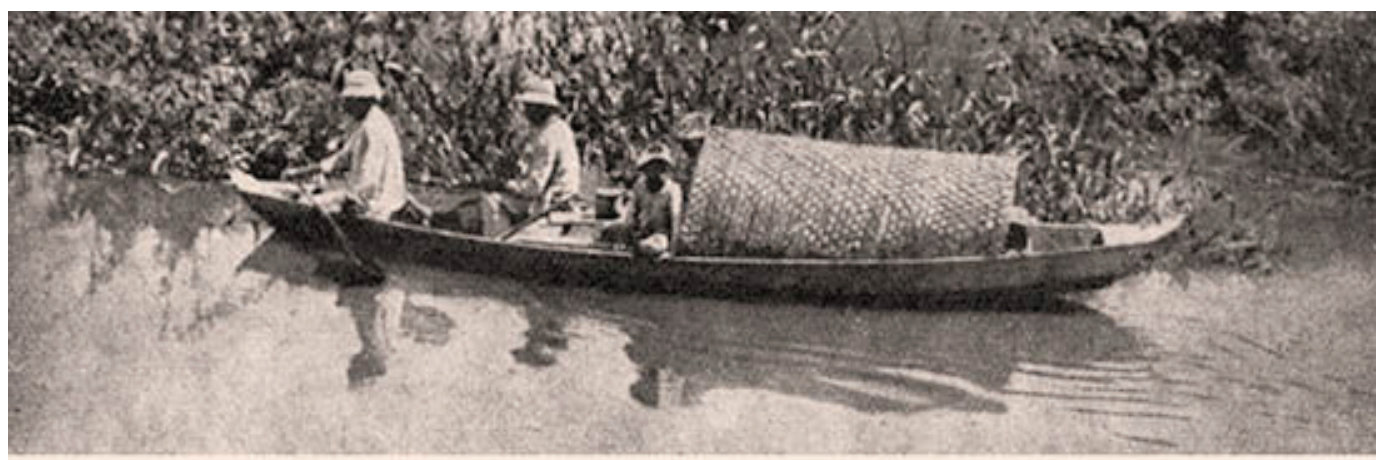

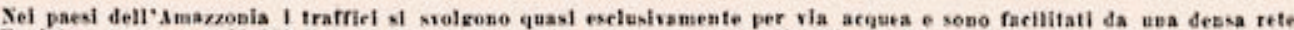

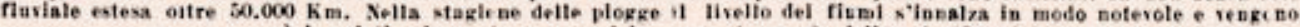
cosi Inondati e In parte sommersi I campos (cavase) ed II mato (foresta).

Figura 1: Meio de transporte da população nos rios (La nuova..., 1949)

A matéria traz o título "A nova missão Consolata em Rio Branco" e relata as impressões dos missionários acerca do que viram em suas primeiras incursões. Na Figura 1, vê-se uma embarcação com capacidade aproximada para três pessoas, metade dela coberta com vegetação seca, bem como madeira para flutuação em águas doces. O registro veiculado na página da revista, entendemos, funciona como prova do que foi escrito, ratificando as dificuldades encontradas, apesar do relato das belezas naturais.

A legenda destaca o meio de transporte utilizado, as características climáticas da região e as peculiaridades do período chuvoso em área de floresta. Na imagem é possível apreender 
o que entendemos ser o desejo dos religiosos de se apropriar do campo, buscando entender suas características por meio dos elementos que o compõem. Compreender o campo é transitar por suas peculiaridades, é pensar de forma relacional, prever seus movimentos, a fim de extrair dele o capital objetivado e preparar investimentos futuros (Bourdieu, 1989).

Ter o olhar direcionado para a legenda é ser conduzido pela lente do editor, significa ver o que ele quer. Chama atenção a cautela com as legendas, que direcionam o olhar para algumas coisas, mas não iluminam outras. Isso ocorre porque os editores usam lentes especiais para fazer o leitor crer no que foi escrito. Assim, entram em cena os "óculos especiais", que selecionam e constroem o que é selecionado, direcionando o foco para o que é interessante destacar (Bourdieu, 1997).

Advertidos, coube-nos perscrutar a imagem para ver o invisível. A respeito dos trajes, infere-se que os corpos se adaptam às hostilidades impostas por aquele cenário. Assim, a assimilação de novos códigos simbólicos parecia entrar em curso, provocando a necessidade de interpretar o campo e assumir novas posturas que deveriam ser aprendidas (Bourdieu, 1997).

A mesma matéria do periódico relata que na região havia predominância das etnias macuxi e wapixana, mas ressalta a presença de taurepangs, caribes, bem como de indígenas venezuelanos, com dois registros imagéticos (Figuras 2 e 3 ).

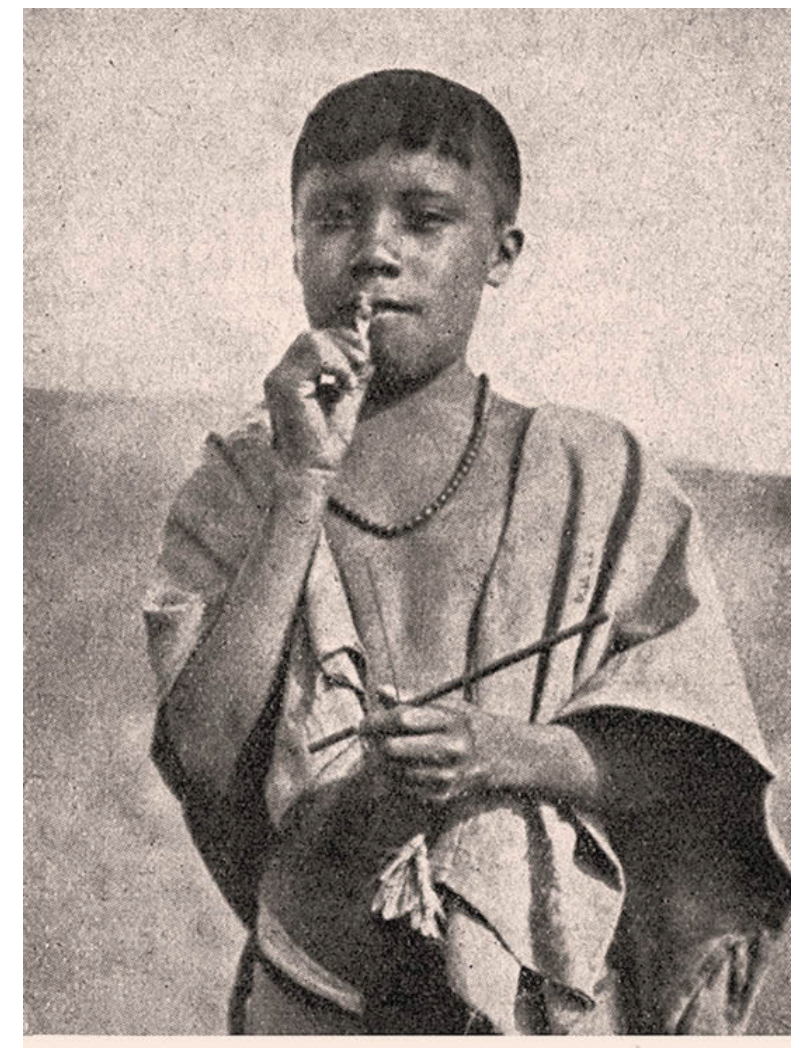

Tipo di ragazzo indio del Rio Branco. I ragazzi dell'Amazzonia sono abili cacciatori di locuste, che poi divorano con gusto dopo averle arrostite infilzate al gambo di un giunco.

Figura 2: Índios da região (La nuova..., 1949) 
Mais uma vez, o editor utiliza a estratégia de prova e apresenta aos leitores imagens da população indígena. A Figura 2 traz a imagem de um jovem indígena (a matéria não é clara quanto a sua etnia) segurando em uma das mãos o que parece ser um graveto.

Pela análise da legenda, o garoto indígena demonstra comportamento peculiar aos indígenas, exibindo hábitos de caçar animais e insetos e degustá-los. Cremos que os religiosos tinham a preocupação de retratar os detalhes do campo, configurando o cenário de um jogo que, embora não possuísse regras deliberadas, movia-se em função dos objetos em disputa (Bourdieu, 1989).

As imagens fotográficas de indígenas veiculadas em distintos meios de divulgação, principalmente no século XIX e início do século XX, apelavam para o exótico, em detrimento de aspectos etnográficos (Tacca, 2011). Ainda conforme o autor, o objetivo estava mais relacionado ao aguçamento do imaginário, ou seja, o fascínio pelo diferente e incomum, do que à precisão das informações sobre, por exemplo, as características das etnias cujas imagens eram capturadas.

Esse aspecto é comprovado na dificuldade dos missionários em estabelecer a quantidade de índios encontrados em suas primeiras incursões, assim como distinguir as etnias e seus respectivos hábitos e costumes. No entanto, a predominância das etnias macuxi e wapixana é frequentemente relatada em pesquisas sobre a região do Rio Branco e em trabalhos que narram os primeiros contatos com os indígenas no período colonial (Vieira, Gomes Filho, jul.-dez. 2015).

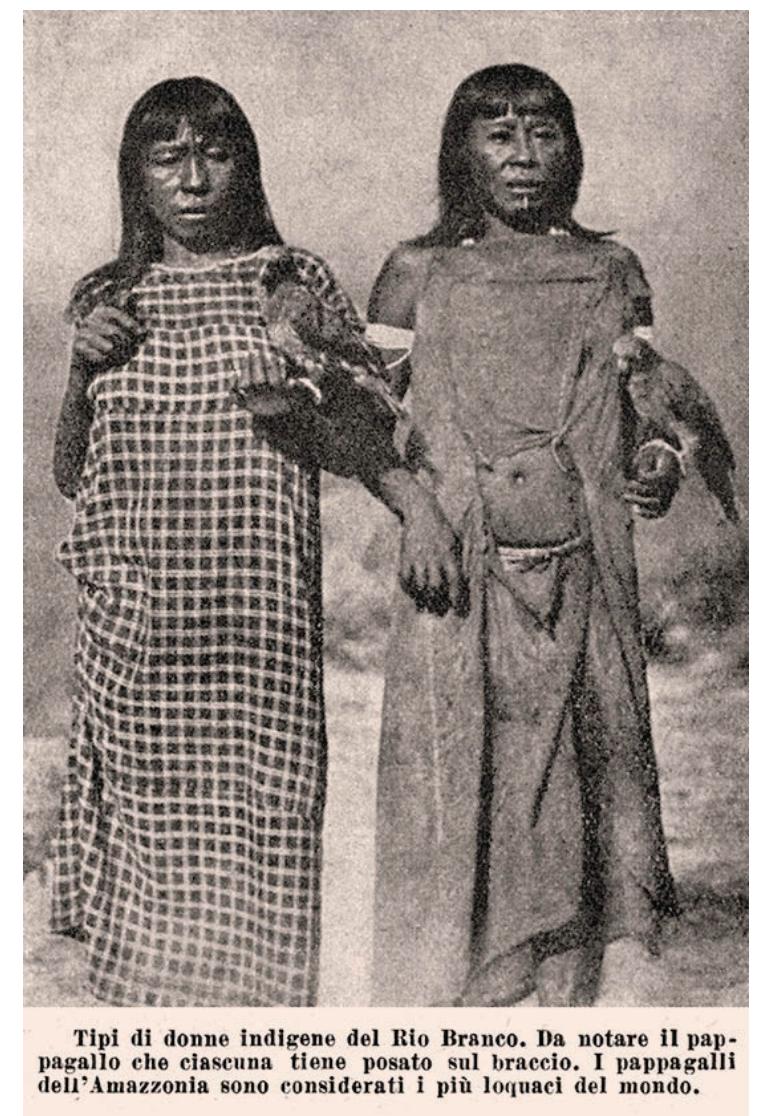

Figura 3: Índios da região (La nuova..., 1949) 
A Figura 3 mostra duas mulheres indígenas cuja etnia também não foi precisada. Apresentar as imagens em meio ao texto é mostrar o recorte no tempo e espaço do habitus dos índios. A imagem aponta para além de trajes e características físicas que, decodificados, evidenciam os saberes e práticas de cada etnia, o que naquele momento não era o objetivo, mas sim sinalizar diferenciação do estatuto social de índios e não índios.

No olhar crítico, a matéria ressalta o exótico, o que nos direcionou à abordagem crítica de Tacca (2011, p.203) sobre a predominância nas distintas imagens que registram interações entre índios e não índios no início do século XX, "do domínio do corpo de nativos como espetáculo visual". Pela distinção, na leitura das entrelinhas, que o texto fez de quem era civilizado e não civilizado, subentendemos a superioridade (Tacca, 2011) de um agente em relação ao outro no simples ato de capturar uma imagem. Nos relatos, os missionários apresentavam o que lhes chamava a atenção, ao mesmo tempo em que salientavam as dificuldades encontradas.

Para iniciar suas estratégias, os Consolata mantinham suas instalações no pequeno município de Boa Vista junto à prelazia, onde realizavam atividades eclesiais. Mantiveram escolas religiosas nas aldeias indígenas mais próximas do povoado e realizavam viagens de desobriga (missas itinerantes) nas localidades indígenas próximas a Boa Vista. A localização dos Consolata trazia uma estratégia de dominação, fosse ela direta ou indireta (Bourdieu, 1989, 1996).

De 1948 a 1953, os missionários deram continuidade ao que os beneditinos faziam. Isso ocorreu devido à manutenção da ordem local, que cabia à Igreja, com as forças políticas locais para manter clima de cordialidade e certa obediência. A ordem deveria ser mantida, sustentada pelo discurso do Estado de que os interesses gerais eram atendidos.

Ter o olhar crítico para esse fato é pensar de forma a deslocar a posição de juiz. Isto é, deixar de entender de maneira cordial e obediente e seguir o exame atento para a narrativa histórica. Nesse olhar, podemos mencionar que os missionários iam a cavalo em suas visitas aos indígenas e, segundo eles, encontravam índios em fase mais adiantada de civilização. Na matéria intitulada "Le missioni del Rio Branco" (As missões do Rio Branco) de 1951, mais uma vez a estratégia dos editores foi o recurso visual (Figuras 4 e 5).

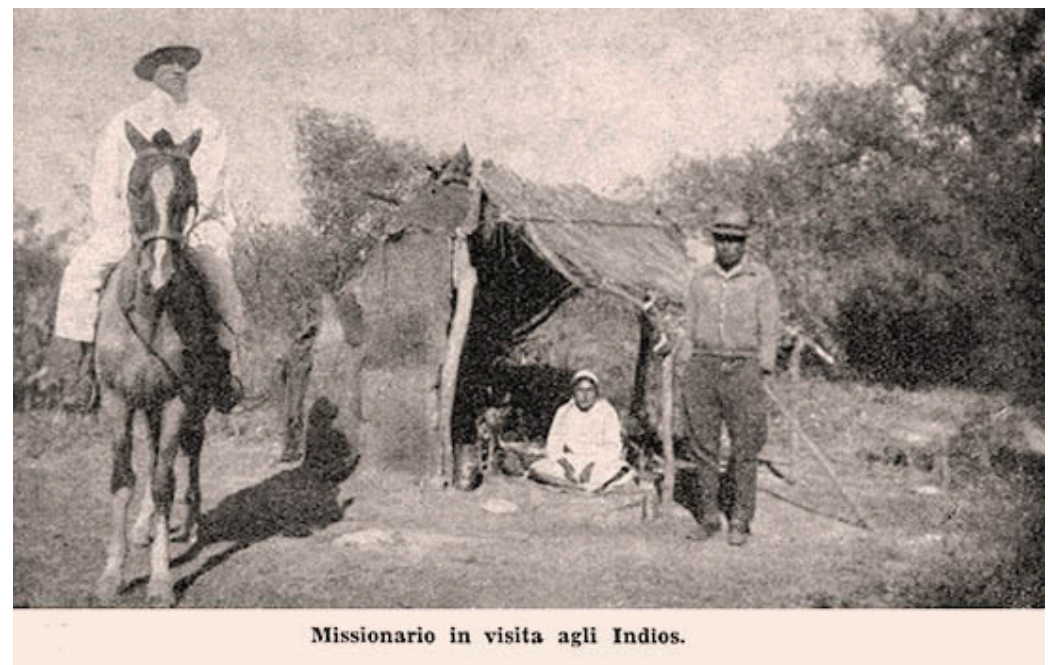

Figura 4: A missão em Rio Branco (Fiorina, 1951) 


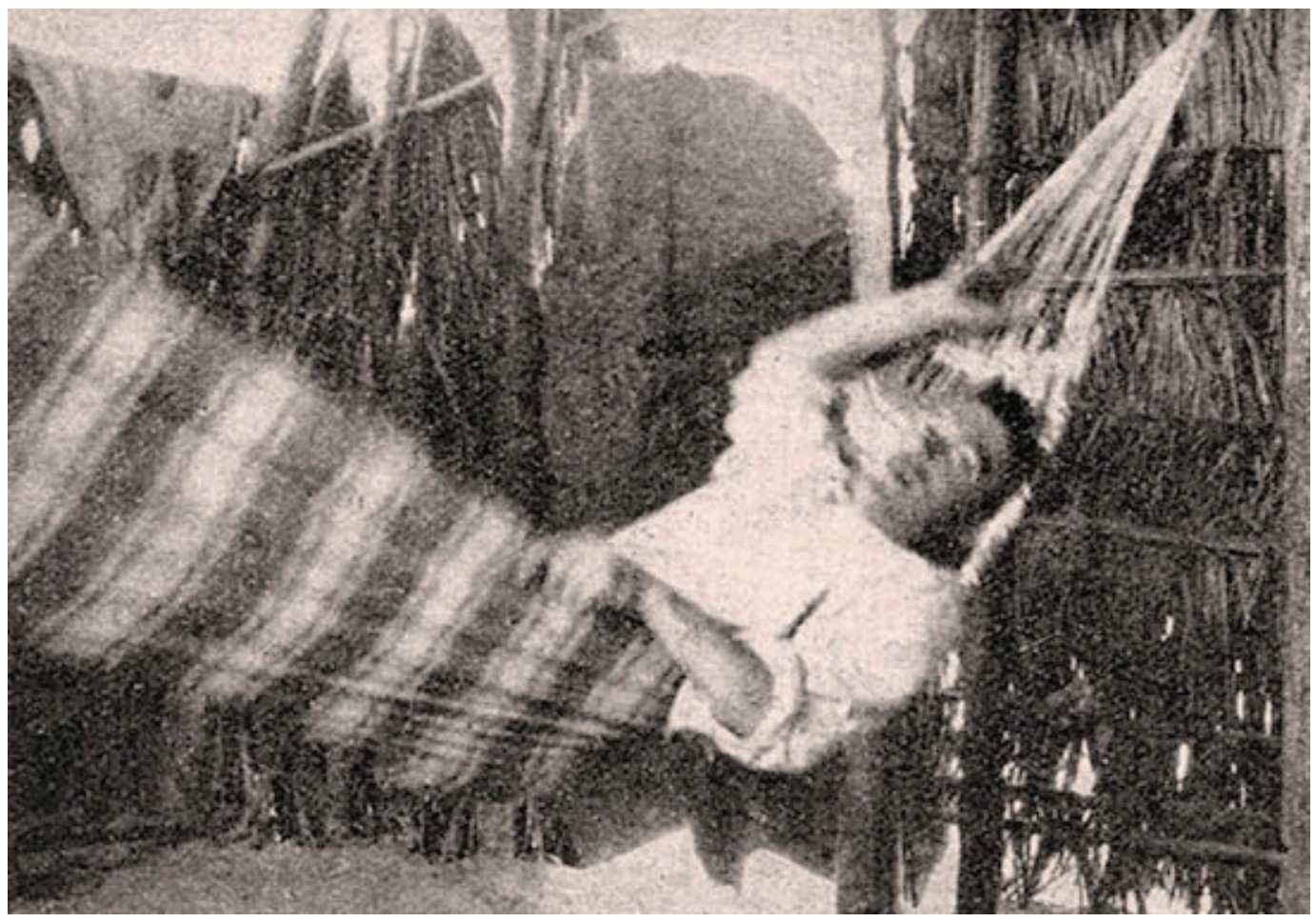

Figura 5: A missão em Rio Branco (Fiorina, 1951)

Nessas imagens observamos um missionário a cavalo e caboclos em trajes sociais (Figura 4), e religioso dormindo em uma rede (Figura 5). Pressupomos que o trabalho missionário fluía, mas, como dito antes, coube aos beneditinos parte dos resultados, considerando que os Consolata encontraram trabalho anterior já feito, independentemente do modus operandi utilizado.

Os missionários da Consolata agiam como se a libertação e organização política dos indígenas pudesse ocorrer de forma gratuita. Embora nada fosse pago, era a busca da razão de ser da conduta de fins econômicos.

Para alguns, isso pode soar estranho, mas significa inculcar que era gratuito entender de onde o agente (índio) vem, ou seja, suas origens. O que implica a noção de illusio, que, decodificando, estabelece o que vale para quem joga. Mas para quem está fora do jogo, cabe se perguntar se vale a pena o jogo. Logo, nesse jogo a illusio é uma relação mágica/ encantada que envolve as estruturas mentais e objetivas do espaço social, ou seja, o que vale é o sentido do jogo (Bourdieu, 1996).

No olhar crítico, desloca-se o exercício da exploração para a transposição do sentido (Osório, 2005). Esse sentido envolvia os missionários para além da cordialidade e obediência política. Tratava-se de dominar em prol de seus interesses, com um discurso maior de proteção aos índios. Nesse ínterim, os missionários se dedicavam à imersão na cultura indígena. Isso pode ser evidenciado na edição da Missioni Consolata de 1952, que traz uma matéria em que um missionário se dispõe a aprender, por exemplo, a usar arco e flecha (Figura 6). 


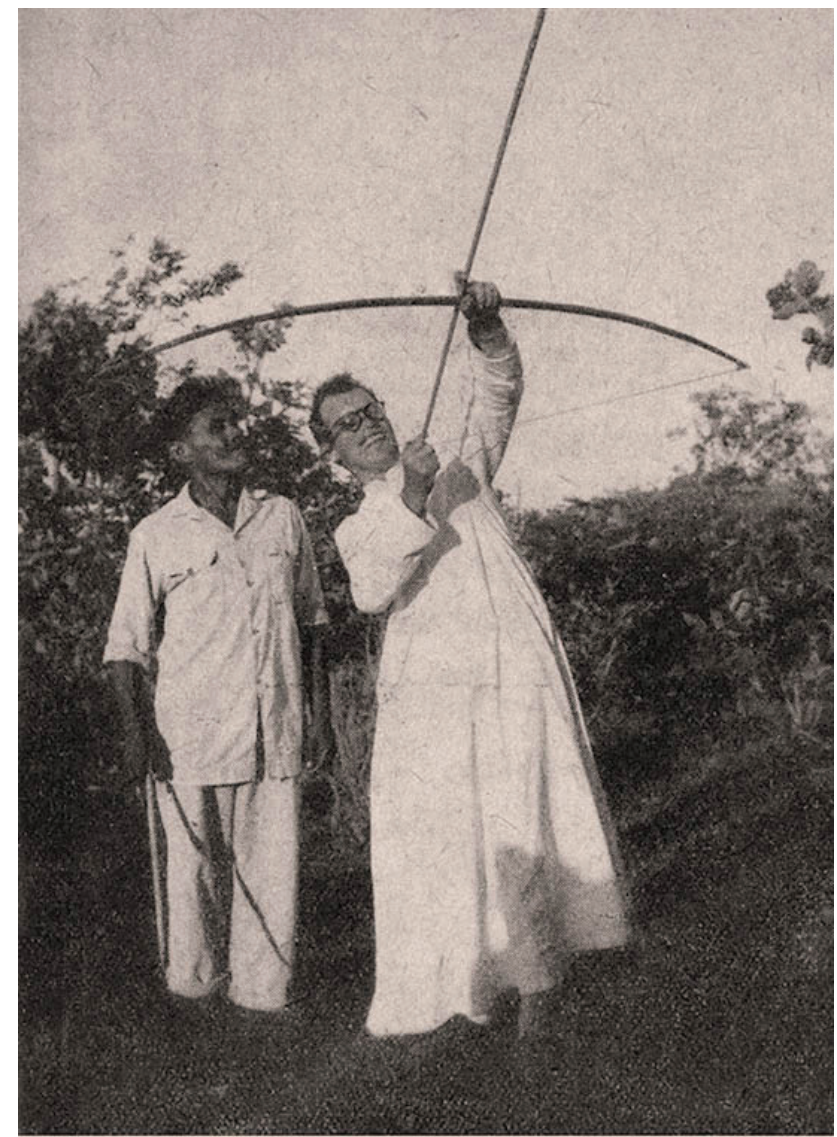

Il P. Silvestri alle prese con l'arco e con le frece.

Figura 6: Quarenta dias ao sul de Rio Branco (Silvestre, 1952)

A Figura 6 nos chama atenção pelo religioso que, ao lado de um nativo e com os paramentos religiosos, porta um arco e flecha. Não nos cabe ver de forma ingênua ou desinteressada a predisposição de imersão na cultura indígena. Trata-se de cálculo consciente, quando o habitus e o espaço social possuem relação direta de cumplicidade como sentido envernizado de dominação indireta (Bourdieu, 1996).

É possível entender que aprender a cultura do outro também pode ser estratégia e projeto (missão) de se impor no espaço social. Isso faz sentido no registro de que missionários realizavam missas e batismos naquela população (Dalmonego, Moiola, 2017). Para a cultura nativa dos índios, tais ritos são adversos em sua essência, considerando suas práticas com base no ritos xamânicos (Kopenawa, Albert, 2015).

Com relação à imersão dos missionários na cultura indígena, tendo por ideologia respeitar seus hábitos e costumes, entendemos como estratégia para posterior introdução de elementos sociais fora da cultura nativa. Isso implica reconfigurar o habitus do nativo (índio ou caboclo) no sentido de socializá-lo em outro corpo estruturado que tem por efeito deixar sua cultura, no mínimo, híbrida. 
Retratar um missionário com arco e flecha, à primeira vista, pode inferir uma visão poética, mas, retirado o verniz, a estratégia empreendida é evidenciada. Possivelmente, a ação era desinteressada, porém, os objetivos invisíveis reluzem, apoiados na intenção de provocar interações com os nativos, o que configura verdade subjetiva e realidade objetivada (Bourdieu, 1996).

O batismo é um rito simbólico de inserir o outro em determinado grupo, que pode ser entendido como família. É uma construção na estrutura mental, deslocar o olhar de onde se estava para onde se quer que outro fique/olhe e socializá-lo aos interesses de maneira quase mágica, é transportá-lo para outro coletivo do qual não fazia parte antes (Bourdieu, 1996). Logo, é inculcar dogmas por meio de ritos e palavras, pois a água lava/limpa o antes para o agora/depois.

É a aceitação em outro grupo com privilégios simbólicos, desde que obedeça à ordem instituída. Pensar nessa lógica remete à ponta do iceberg dos cuidados objetivos e subjetivos. Tentar convencer os índios do que era melhor para eles, dominação indireta, por meio da violência doce, quando o envolvido pode ser sensibilizado para outras intervenções.

Entender os missionários como agentes ideológicos da Igreja é, também, permitir-se ter um olhar crítico quanto às estratégias empreendidas para a conquista de seus interesses de catequização em nome da salvação do corpo e da alma. Outra estratégia identificada e usada pelos missionários foi a das publicações, mesmo que em italiano, pouco lido e entendido no Brasil, voltadas para os mais interessados nessas questões e poliglotas.

O periódico, ao circular na Itália, produzia efeito da crença estabelecida na missão, mas, por outro lado, mesmo no Brasil, para aqueles que não entendiam o idioma ou mesmo os analfabetos, as imagens transmitiam significados, por meio do repertório de cada leitor em suas representações sobre os aspectos da religão católica.

Enfim, lacunas foram deixadas, por exemplo acerca do detalhamento dos cuidados inseridos pela missão dos beneditinos, mas elas são fendas que se abrem para outros estudos. Por outro lado, o entendimento das lacunas do texto e do contexto da discussão é algo obtido ao empreender-se uma aproximação maior com o tema e manter-se o rigor metodológico para objetivação da síntese, afinal, trata-se de narrativa histórica em construção.

O olhar cultural revela as contribuições para a área de saúde. Talvez sejam poucos os estudos empreendidos nessa área do conhecimento, atualmente mais preocupada com a avalancha de investigações baseadas em evidências do que com aspectos socioculturais do passado, como se o presente se construísse a partir do agora.

Entender os meandros dos cuidados dedicados pelos antecedentes, mesmo que sem profissionais de saúde, é ampliar o campo intelectual. Em especial a respeito de estratégias que, apesar de terem sido aplicadas em tempos idos, são reatualizadas por muitos quando em campo trabalhando diretamente com saúde indígena.

Duas matérias do periódico foram selecionadas, totalizando seis imagens articuladas ao texto e contexto. São registros dos aspectos locais e da cultura indígena, em que o periódico apresentava aos leitores as ações produzidas pelos religiosos no campo para dominação estratégica de seus interesses. Os registros, aliados à retórica do Estado pela ordem estabelecida e a dominação, descortinam as estratégias empreendidas pelos missionários da Consolata. 
Identificar algumas estratégias empreendidas por esses agentes foi retirar o verniz ideológico religioso para visualizar, de forma intelectual, as pretensões do que estava em jogo. O fato de o batismo ser entendido como forma de cuidado e inserção em uma família visava salvar o corpo e a alma. Nessa perspectiva, cuidados culturais indígenas até poderiam ser usados, mas cabia a intervenção do campo da saúde, por meio de seus elementos e profissionais, para atuar, possivelmente, com o discurso e a prática, tendo em vista a prevenção e o tratamento em prol da saúde.

Cabe ainda examinar outros documentos para a consolidação do discurso. Por outro lado, importa esclarecer que nossa intenção não é estacionar a investigação por aqui. Assim, a presente pesquisa deve ser entendida como proposta problematizadora para outros estudos.

\section{NOTA}

${ }^{1}$ Em 1962, o território federal do Rio Branco, passou a ser denominado território federal de Roraima, por meio de lei de autoria do então deputado roraimense Valério Caldas de Magalhães. A Constituição de 1988 elevou o então território a estado, passando a denominar-se estado de Roraima.

\section{REFERÊNCIAS}

ARAÚJO, Melvina Afra Mendes de.

Missionários, Kikuyu e Mau Mau: pontos de convergência em situações de conflito. Revista Aulas, n.4, p.1-32. Disponível em: <http://www. unicamp.br/ aulas/Conjunto\%20II/4_18.pdf>. Acesso em: 22 jul. 2018. 2007.

BERNARDES, Margarida Maria Rocha et al. Método de análise imagética: Cazuza na revista Veja como ícone da aids na década de 1980 no Brasil. Psicologia e Saber Social, v.4, n.2, p.183194. Disponível em: <http://www.e-publicacoes. uerj.br/index.php/psi-sabersocial/article/ view/16192>. Acesso em: 30 ago. 2018. 2015.

BOURDIEU, Pierre.

Sobre a televisão. Rio de Janeiro: Jorge Zahar. 1997.

BOURDIEU, Pierre.

Razões práticas sobre a teoria da ação. São Paulo: Papirus. 1996.

BOURDIEU, Pierre.

O poder simbólico. Rio de Janeiro: Bertrand Brasil. 1989.

CASTELNAU-L'ESTOILE, Charlotte de. Interações missionárias e matrimônios de índios em zonas de fronteiras (Maranhão, início do século XVII). Tempo, v.19. n.35, p.6582. Disponível em: <www.scielo.br/pdf/tem/ v19n35/05.pdf>. Acesso em: 7 set. 2018. 2013.

DALMONEGO, Corrado; MOIOLA, Paolo (Org.). O encontro Nohymayou - memórias da Missão Catrimani: construindo relações de alianças com o povo Yanomami. São Paulo: Paulinas. 2017.
FIORINA, Domenico.

Le missioni del Rio Branco. Missioni Consolata, ano 53, n.10, p.282-285. 1951.

FREIRE, Maria Martha Luna.

Mulheres, mães e médicos: discurso maternalista em revistas femininas (Rio de Janeiro e São Paulo, década de 1920). Tese (Doutorado em história das ciências) - Casa de Osvaldo Cruz/ Fiocruz, Rio de Janeiro. 2006.

GASBARRO, Nicola.

Missões: a civilização cristã em ação. In:

Montero, P. (Org.). Deus na aldeia: missionários, índios e mediação cultural. São Paulo: Globo. 2006.

GERÔNIMO, Vanessa.

A teoria de transcriação de Haroldo de Campos: o tradutor como recriador. Jornal Eletrônico Qorpus. Editorial 13. Disponível em: <http:// qorpus.paginas.ufsc.br/como-e/edicao-n-013/ateoria-da-transcriacao-de-haroldo-de-camposo-tradutor-como-recriador-vanessa-geronimo/>. Acesso em: 20 abr. 2018. 2014.

KOPENAWA, Davi; ALBERT, Bruce.

A queda do céu: palavras de um xamã Yanomami. São Paulo: Companhia das Letras. 2015.

LA NUOVA...

La nuova missione della Consolata nel Rio Branco. Missioni Consolata, ano 51, n.5, p.99-105. 1949.

MAUAD, Ana Maria.

Através da imagem: fotografia e história interfaces. Tempo, n.2, v.1, p.73-98. Disponível 
em: <http://www.historia.uff.br/tempo/artigos_ dossie/artg2-4.pdf>. Acesso em: 10 set. 2019. 1996.

MONTERO, Paula.

Índios e missionários no Brasil: para uma teoria da mediação cultural. In: Montero, P. (Org.). Deus na aldeia: missionários, índios e mediação cultural. São Paulo: Globo. 2006.

OSÓRIO, Luiz Camillo de.

Razão da crítica. Rio de Janeiro: Jorge Zahar. 2005.

PEREIRA, Elaine Aparecida Teixeira.

O conceito de campo de Pierre Bourdieu: possibilidades de análise para pesquisas em história da educação brasileira. Revista Linhas, v.16, n.32, p.337-356. Disponível em: <http:// www.revistas.udesc.br/index.php/linhas/article/ view/1984723816322015337>. Acesso em: 22 jul. 2018. 2015.

PORTO, Fernando; FREITAS, Genival; GONZÁLEZ, José.

Fontes históricas e ético-legais: possibilidades e inovações. Revista Cultura de los Cuidados, v.13, n.25, p.43-53. 2009.

PORTO, Fernando; NETO, Mercedes. Enfermeira na imprensa ilustrada brasileira (1890-1925): assinatura imagética. Revista Patrimônio e Memória, v.10, n.1, p.199-221. Disponível em: <http://pem.assis.unesp.br/ index.php/pem/article/viewFile/421/737>. Acesso em: 11 set. 2019. 2014.

SANTILLI, Paulo.

Política e ritual: a faina missionária beneditina entre os Macuxi no Vale do Rio Branco. Revista Patrimônio e Memória, v.10, n.2, p.35-61.
Disponível em: <https://repositorio.unesp. br/bitstream/handle/11449/124660/ ISSN1808-1967-2014-10-02-17-34. pdf? sequence $=1 \&$ is Allowed $=\mathrm{y}>$. Acesso em: 13 ago. 2018. 2014.

SILVA, Aramis Luis; ARAÚJO, Melvina Afra Mendes de.

"Fé na cultura": índios, missionários e códigos de mediação. Horizontes Antropológicos, v.13, n.27, p.165-182. 2007.

SILVESTRE, Ricardo.

Quaranta giorni sul Rio Branco. Missioni Consolata, v.54, n.6, p.127-132. 1952.

TACCA, Fernando de.

O índio na fotografia brasileira: incursões sobre a imagem e o meio. História, Ciências, SaúdeManguinhos, v.18, n.1, p.191-223. Disponível em: <http://dx.doi.org/10.1590/S010459702011000100012>. Acesso em: 9 set. 2019. 2011.

VANGELISTA, Chiara.

Missões católicas e políticas tribais na frente de expansão: os Bororo entre o século XIX e o século XX. Revista de Antropologia, v.39, n.2, p.165-197. Disponível em: <http://www.revistas. usp.br/ra/article/view/111659/109690>. Acesso em: 11 set. 2019.1996.

VIEIRA, Jaci; GOMES FILHO, Gregório. Forte São Joaquim: de marco da ocupação portuguesa do Vale do Rio Branco às batalhas da memória: século XVIII ao XX. Texto e Debate, v.28, p.117-136. Disponível em: <https://revista.ufrr.br/textosedebates/article/ download/3390/1897>. Acesso em: 28 ago. 2018. jul.-dez. 2015. 